\title{
PROGRESS REPORT ON THE HISTORY OF FOREST FIRES IN YELLOWSTONE NATIONAL PARK
}

\author{
Richard A. Levinson and Ronald W. Marrs \\ Remote Sensing Laboratory \\ Department of Geology \\ University of Wyoming \\ January, 1978
}

This report discusses a research effort to determine the utility of remotely sensed data to delineate a forest fire history for Yellowstone and Grand Teton National Parks. Research was supported by the National Park Service and the Northern Rocky Mountain Parks Studies Cooperative Program. We are grateful for the cooperation and assistance given us by Dr. Don Despain and other personnel of the National Park Service who provided data and logistical support for this research. We also thank Dr. Dennis Knight and Mr. Bill Romme of the Department of Botany, University of Wyoming, for their assistance in gathering field data essential for evaluation of the remote sensing techniques.

\section{Study Objectives}

The goal of this research was to develop a technique by which we could use remote sensor data to quickly and efficiently identify and map burned areas and then determine the relative age and condition of re-growth in each burned area. We hoped to apply these techniques throughout Yellowstone and Grand Teton National Parks to produce a map and an interpretation of burn histories. These products were to aid in determining the natural ecological succession of the forests in Yellowstone and Grand Teton National Parks and the effect of man upon the natural succession.

\section{Methods}

The work was begun in summer, 1977, with the gathering of available literature, air photos, satellite imagery, and maps for the area. We then selected a smaller test area in which to develop interpretation procedures which would allow us to extract the necessary information from the image data. The Department of Botany at the University of Wyoming was just beginning a sister study which involved the analysis of forest fire history in Yellowstone National Park using dendrochronological and phytosociological techniques. We had planned to use these same techniques in our initial test area to "calibrate" our interpretation of the burned areas identified from imagery. Conversely, the Department of Botany had planned to use aerial photographs as a mapping tool. We, therefore, determined that it would be most expedient to cooperate by selecting a common test area in which we could combine our field mapping efforts. The watershed of the Little Firehole River was selected as the initial test area. 
A preliminary interpretation of this area was made from high-altitude, 1:120,000 scale photography flown by NASA in 1969 (MX 101, 1 ine 2). Though this photography is severely underexposed, we were able to make an interpretation which served as a base upon which to begin the field mapping. An area of approximately $42.7 \mathrm{~km}^{2}\left(16.5 \mathrm{mi}^{2}\right)$ surrounding Little Firehole Meadows (called Little Firehole Meadows study area) was mapped on the ground and determinations were made of age, structure, and species composition of the forest in each portion of the study area. Table I lists the types of ground investigations and analyses performed during the 1977 summer field season.

In spite of the poor quality of the aerial photography used in compiling the preliminary photo map, the interpretation showed a positive correlation to the field map compiled during the summer. Field work indicated that most of the present forests in the study area started as re-growth after forest fires, and that ancient burn areas can be recognized and mapped as changes in the character (appearance) of the forest interpretable from aerial photography. The photo-interpretation was checked on the ground. Major changes in forest character observed on the photos were found to represent 1) different forest types, 2) forests of different age, or 3) forest structure differences due to causes other than species or age differences ( $i . e$. beetle, mistletoe, or fungus infestations, topographic, or moisture changes).

Though the 1969 aerial photography was adequate for the preliminary photointerpretation, better photography had to be obtained in order to effectively apply spectral analysis and densitometry as an aid in forest mapping. The National Park Service had low-altitude color photography which they made available to us (ETZ series, 1969-1971). The detail of this $1: 16,000$-scale stereo photography proved ideal for compiling fire history maps. However, the color values displayed on the photography are unreliable. Many of the prints are too yellow or too red, and some show marked variation in color across each frame which is not related to the true scene colors. Thus, the $1: 16,000$-scale color photo could not be used for spectral analysis.

Recent work has shown that color infrared imagery is especially useful for forest reconnaissance (Ashley, M.D. and Rea, J., 1975; Golden, M.S., 1974; National Academy of Sciences, 1970; Thorley, G.A., 1975). This is because the reflectivity of vegetation in the near-infrared spectral region is very sensitive to changes in condition of that vegetation.

In order to obtain inexpensive photography which would supply reliable information, we decided to fly over the Little Firehole Meadows study area and photograph it in color infrared. On october 18, 1977, we chartered a flight over the study area and obtained high-quality, low-altitude coverage in $70 \mathrm{~mm}$ color infrared and $35 \mathrm{~mm}$ color formats.

Selected frames of the $70 \mathrm{~mm}$ color infrared photography were subsequent ly processed via the video image analysis system at the University of Wyoming Remote Sensing Laboratory (Levinson, R.A., Marrs, R.W., and Grantham, D.G., 1976). Two small test areas $(\approx 6 \mathrm{ha}$. each) were selected for thorough spectral and densitometric evaluation. Site $l$ is an area $1 / 2 \mathrm{~km}$. southwest of Little Firehole Meadows, and contains a 525-year-old spruce-fir forest adjacent to a dense 180-year-old lodgepole pine forest. Site 2 is an unmapped area $2 \mathrm{~km}$. east of Little Firehole Meadows which contains a dense forest stand adjacent to an open stand, with a pronounced forest discontinuity in between. Enhancements 
and analyses to be performed for each test site include: 1) scale adjustment, 2) color separation, 3) linear and logarithmic contrast stretching, 4) band compositing, 5) band subtraction and subtraction compositing, 6) ratio and ratio compositing, 7) density contouring, and 8) edge-enhancement. Spectral analyses of these test areas are still in progress, but preliminary results show that useful information can be obtained from video image analysis. Information derived from the processed imagery includes a detailed map of the test sites, tree density and percent cover, density of dead trees, type and percent cover of undergrowth, and information on tree size and shape.

Analysis of LANDSAT-1 MSS imagery (image \#1015-17404, 7 Aug. 72, and image \#1195-17414, 3 Feb. 73) was begun in autumn, 1977. The 7.3 inch positive transparency $1: 1,000,000$ format was used. All four spectral bands were analyzed for patterns similar to those which had proved significant on the preliminary photo-interpretation map and the field map. However, no pattern correlation between these maps and the LANDSAT imagery was apparent.

We also attempted to evaluate digitally processed LANDSAT data which was made available to us by the National Park Service. Alpha-numeric maps of unsupervised classifications had been constructed using composite-sequential and K-means clustering techniques [produced by the Laboratory for Applications of Remote Sensing, Purdue University (Coggeshall, M.E., and Hoffer, R.S., 1973)]. These were compared to the photo-interpretations and the field map to determine the significance of the alpha-numeric map units. Though these digital studies are not yet complete, it appears that the resolution of the LANDSAT data $(\approx 1$ ha.) is not adequate to discriminate the detail of individual forest stands which is essential to mapping and evaluation of burn areas.

Summary of Significant Results

Progress to date includes the following items:

1. A preliminary forest map of the Little Firehole River watershed interpreted from $1: 120,000$-scale photography was completed.

2. A field map of the Little Firehole Meadows test area showing sampled forest stands, approximate forest boundaries, and approximate ages of forests was compiled.

3. Analysis of summer and winter LANDSAT imagery has shown that the 1 ha. resolution of the LANDSAT scanner system is too broad to detect individual forest stands and their boundaries.

4. Video processing of low-altitude, color infrared photography has shown that the logarithmically contrast-stretched band composite is a particularly useful enhancement for forest mapping.

5. Qualitative information may be obtained from video processed imagery. This includes identification of burn areas, live trees, dead trees, and undergrowth, and information on tree size and shape. Some of this information is not readily interpreted from un-processed imagery.

6. Quantitative data may also be derived from video processed imagery. This includes areal measurements, live tree density and percent cover, dead tree density, and percent cover of undergrowth. 
Our results show that detailed photographic data are essential for the compilation of the "fire history" maps. We will not be able to compile such maps from high-altitude aerial photography or satellite imagery. Therefore, we will not be able to produce regional maps of Yellowstone and Grand Teton National Parks as we had hoped. However, the low-altitude photography provides much useful information for locating burn areas and determining fire histories. Video processing aids in the interpretation of this photography. Our research work has defined several useful techniques, and should yield a demonstration of the utility of remote sensing in the study of forest fire histories.

\section{Literature Cited}

Ashley, M.D., and Rea, J., 1975. Spruce budworm damage evaluations from color infrared photography. Remote Sensing of Earth Resources V. 4, Shahrokhi, F., ed., Univ. of Tenn., Space Inst., Tullahoma, Tenn., p. 387-401.

Coggeshall, M.E., and Hoffer, R.M., 1973. Basic forest cover mapping using digitized remote sensor data and ADP techniques. LARS Information Note 030573 , Purdue University, $171 \mathrm{p}$.

Golden, M.S., 1974. The use of small-scale imagery for the location of pines infested by the southern pine beetle. Remote Sensing of Earth Resources, V. 3, Shahrokhi, F., ed., Univ. of Tenn., Space Inst., Tullahoma, Tenn., p. 353-359.

Levinson, R.A., Marrs, R.W., and Grantham, D.G., 1976. Rapid, low-cost image analysis through video processing. ERDA Open-File Report GJBX-37(76), 54 p.

National Academy of Sciences, 1970. Remote sensing with special reference to agriculture and forestry. Washington, D.C., $424 \mathrm{p}$.

Thorley, G.A., 1975. Forest lands: inventory and assessment. Manual of Remote Sensing, Reeves, R.G., ed., Am. Soc. of Photogrammetry, Falls Church, Va., p. 1353-1426.

Acknowledgments

Assisted by: Drs. Don Despain and Dennis Knight

Field Assistance by: Mr. Larry Van Dusen and Mr. Bill Romme

Supported by: Northern Rocky Mountain Parks Studies Cooperative Program and the National Parks Service 
Table I. FIELD INFORMATION GATHERED FOR EACH FOREST STAND SUMMER, 1977

Basic and Physical Data

Stand Number Assignment

Forest Type

Map Location

Approximate Stand Size

Elevation

Slope and Aspect

Drainage

Age Data

Sampling of Trees (Cores)

Ring Counts

Growth History

Forest Structure Data

Species Identification. (Id.)

Tree Height

Tree Density*

Tree Diameter*

Presence of Pine Bark Beetle

Presence of Dwarf Mistletoe

Presence of Other Identifiable Ailments**

Presence of Charcoal

Presence and Orientation of Fire Scars

Presence of Serotinous Cones

Relic Trees--Presence, Species Id., Age, Tree Height

Saplings--Species Id., Density***;

Visible Soil and Rock--Percent Cover, Color, Moisture Content Ground Vegetation--Species Id., Percent Cover

Fuel Inventory****;

General Observations

Evenness of Age and Tree Size

Forest Maturity

Growth Trends

Geological Substrate

Presence of Thermal and Tectonic Activity

Animal Activity

Appearance on Aerial Photography

*Measured for 1)Living Trees, 2) Standing Snags, 3) Fallen Snags

**Blister Rust, Needle Miner, Spruce Bark Beetle, etc.

***Saplings Less than Breast Height

****Litter, Classified by Size, Species Id. where possible, Duff

Layer Thickness 
Table II. WORK SCHEDULE AND EXPECTED COMPLETION DATES

$\begin{array}{ll}\text { Work Item } & \text { Completion Date } \\ \text { Complete digital analysis of LANDSAT data } & \text { February 15, } 1978 \\ \text { Complete video image analysis on test site 1 } & \text { February 28, } 1978 \\ \text { Demonstrate video processing techniques on test site 2 } & \text { March 15, 1978 } \\ \begin{array}{l}\text { Construct forest map of Little Firehole Meadows } \\ \text { test area showing burn areas, forest types, and } \\ \text { forest ages }\end{array} & \text { March 31, 1978 } \\ \text { Compile final report } & \text { May 31, 1978* }\end{array}$

*Our current work schedule calls for completion of this program by April 30 , 1978. The problems with the quality of available photographic coverage have caused unexpected delays. We believe that we can complete the research (as modified according to our results) by May 31, 1978. 